UOT 621.892.28; 678.742

XROM DUZU İLə MODIFIKASIYA OLUNMUŞ KATALITIK KOMPLEKSIN
IŞTIRAKI İLə HEKSEN-1-İN OLIQOMERLOŞMəSI PROSESININ TODQIQİ

\author{
Ş.A.Olizadə
}

\author{
AMEA Y.Mammadaliyev adina Neft-Kimya Proseslari İnstitutu \\ Az 1025, Bakl, Xocall prospekti, 30 \\ Fax: (+99412) 490-24-76, e-mail: selizade180@gmail.com
}

\begin{abstract}
Maqalado alüminium asasl katalitik kompleksi xrom duzu ila in situ rejimdomodifikasiya edilarak oliqomerlaşma proseslarindo ilkin katalitik kompleks va digar alüminium torkibli katalizatorlarla müqayisadə yüksək aktivlik göstərən bimetallik katalitik kompleksin sintezi məsalasina toxunulmuş, bimetallik katalitik kompleksin iştirakı ila heksen-1-in oliqomerloşmasi prosesinin qanunauyğunluqlar tadqiq olunmuşdur. Prosesa müxtəlif parametrlarin tasiri araşdırllmış, proses üçün optimal şarait təyin olunmuşdur. Oliqomerlaşmə məhsullarının tarkibi, bəzi fiziki xassalari fiziki-kimyəvi analiz metodları ila tədqiq olunmuşdur. Müəyyən edilmişdir ki, təyin olunmuş optimal şəraitdə xrom duzu ilo modifikasiya olunmuş katalitik kompleksin iştirakı ila heksen-1-in oliqomerlaşməsi zamanı yüksək çıxım va fizikimexaniki göstaricilara malik polialfaolefin yağları almaq mümkündür.
\end{abstract}

Açar sözlor:modifikasiya, oliqomerlaşma, katalitik kompleks, heksen-1, polialfaolefin yağlar

DOI:10.32737/2221-8688-2019-3-444-449

$\alpha$-Olefinlər əsasında sintetik yağların sintezi aktual elmi tədqiqat sahələrindən biri olub, olduqca böyük maraq doğurur vəaşağ 1 donma temperaturuna, yüksək termostabilliyə, oksidləşməyə qarşı davamlılığa, az uçuculuğa, kokslaşmaya və bircins tərkibə malik olması sayəsində polialfaolefin yağları tədqiqatçıların daim diqqət mərkəzində olmuş və bu gün onlar əsasında yüksək keyfiyyət göstəricilərinə malik müxtəlif çeşidli polialfaolefin yağlarıistehsal olunur [1-5]. $\mathrm{Bu}$ yağların tərkibində kükürdlü və metal birləşmələri olmadığından, onlar yükssək antikorroziya xassəsinə malikdir. Eyni zamanda poliefin yağları ilə müqayisədə mineral yağlarla asan qarışdığından, yarımsintetik yağların istehsalında komponent kimi əvəzsizsizdir [613]. $\mathrm{Bu}$ baximdan, $\alpha$-olefinlorin oliqomerləşməsinin daha perspektiv yollarla həyata keçirilməsi istiqamətində tədqiqatlar

\section{Giriş}

aparılır və göstərilmişdir ki, alüminiumun 1,2dixloretanla qarşılıqlı təsirindən alınan katalitik kompleks doymamış karbohidrogenlərin oliqomerləşməsi prosesində yüksək aktivlik nümayiş etdirir [14]. Bununla yanaş1, müəyyənləşdirilmişdir ki, alüminium tərkibli katalitik kompleksin müxtəlif d-elementləri ilə modifikasiyası, daha yüksək aktivliyə malik bimetallik katalitik kompleklərin yaradılmasina imkan verir. Bunlar1 nəzərə alaraq $\alpha$-olefinlərin oliqomerləşmə prosesinin intensivləşdirilməsi, yüksək qaynama temperaturuna malik yă fraksiyalarının alınması üçün daha selektiv və yüksək aktivliyə malik katalizatorların yaradılması məqsədilə xrom duzu ilə modifikasiya olunmuş katalitik kompleksin iştiraki ilə heksen-1-in oliqomerləşməsi prosesi tədqiq olunmuşdur.

\section{Eksperimental hissə}

Alüminium, dixloretan əsaslı katalitik kompleksi (KTK)Cr (III) xloridi ilə modifikasiya etməkləKTK və digər alüminium tərkibli katalizatorlarla müqayisədə oliqomerləşmə proseslərində daha yüksək aktivlik göstərən bimetallik kompleks sintez edilmişdir. Bimetallik katalitik kompleksin sintezi reaksiya gedişində ilkin radikalların yaranma anında sistemə xrom duzunun $\left(\mathrm{CrCl}_{3}\right)$ daxil edilməsi iləin situ rejimində aparılmışdır. Sintez prosesinə temperaturun, reaksiya müddətininin, həlledicinin təbiətinin, komponentlərin miqdqarının, o cümlədən $\mathrm{Al}: \mathrm{Cr}$ mol nisbətinin təsiri araşdırılmış, proses 
üçün optimal şərait təyin olunmuşdur. Sintez olunmuş katalitik kompleksin tərkibi, strukturu müxtəlif fiziki-kimyəvi analiz üsulları ilə tədqiq olunmuşdur [15-18]. KTK və $\mathrm{KTK} / \mathrm{CrCl}_{3}$ iştirak1 ilə müqayisəli şəkildə heksen-1-in oliqomerləşməsi prosesi tədqiq olunmuş, prosesə katalizatorun qatılığının, reaksiya müddətinin, temperaturun və katalizatorun komponentlərinin ( $\mathrm{Al}: \mathrm{Cr}) \mathrm{mol}$ nisbətinin təsiri öyrənilmişdir[19].

\section{Nəticələr və onlarin müzakirəsi}

Heksen-1-in oliqomerləşmə prosesinə katalizatorun qatılı̆̆ının təsirinin tədqiqi zamanı müəyyən olunmuşdur ki, katalizatorun aşağ 1 qatılıqlarında oliqomerləşmə prosesi zəif gedir və oliqomerləşmə məhsulunun çıxımı nisbətən aşağ1 olur. Təcrübələr əsasında müəyyən edilmişdir ki, bimetallik kompleksin qatılığının artırılması nəticəsində proses sürətlənir və katalizatorun $0.4-0.5 \%$ küt. qatılıqlarında heksen-1-in tam çevrilməsinə nail olunur. İlkin KTK ilə olefinin tam çevrilməsinə katalizatorun $0.7-1 \%$ qatılığında nail olunmuşdur. Sistemə katalizator qatılığının $1.0 \%$ küt.-dən artıq verilməsi olefinin sıçrayışla reaksiyaya daxil olmasına səbəb olur və prosesi tənzimləmək mümkün olmur.KTK/CrCl $\mathrm{C}_{3}$ iştirakı ilə heksen-1-in oliqomerləşmə prosesinə reaksiya müddətinin təsiri 10-80 dəq.zaman intervalında tədqiq olunmuşdur.Müəyyən olunmuşdur ki, ilk 10 dəq. müddətində heksen-1-in çevrilməsi aşağıdır və bu səbəbdən oliqomerləşmə məhsulunda $\mathrm{T} \leq 300^{\circ} \mathrm{C}$ fraksiya üstünlük təşkil edir. Reaksiya müddətinin artırılması ilə yüksək molekullu oliqomerlərin çıxımında artım qeydə alınmışdır və 60 dəq.-də 300$450^{\circ} \mathrm{C}$ yağ fraksiyasının maksimal çıxımı müşahidə edilmişdir. Reaksiya müddətinin sonrak1 artımı prosesə, praktiki olaraq təsir göstərmir və proses üçün optimal müddət 60 dəq. hesab olunur. Oliqomerləşmə prosesinə temperaturun təsiri $30-60^{\circ} \mathrm{C}$ intervalında tədqiq olunmuşdur. Təcrübi nəticələrə əsasən müəyyən edilmişdir ki, temperaturun $50^{\circ} \mathrm{C}$ dək yüksəldilməsi prosesin gedişinə müsbət təsir göstərərək heksen-1-in tam oliqomerləşməsini təmin etməklə yanaşı, yüksək özlülüyə malik olan yağ fraksiyasının miqdarının artmasını təmin edir.

Cədvəl. Al:Cr nisbətinin heksen-1-in oliqomerləşmə prosesinə təsiri (katalizatorun qatılığ $1-0.5 \%$ küt., temperatur $-50^{\circ} \mathrm{C}$, reaksiya müddəti -60 dəq.)

\begin{tabular}{|l|c|c|c|c|c|}
\hline \multirow{3}{*}{ Katalizator } & $\begin{array}{c}\text { Al:Cr } \\
\text { mol nisbəti }\end{array}$ & \multicolumn{4}{|c|}{ Yağ fraksiyalarının çıxım1, \% küt. } \\
\cline { 2 - 6 } & & $300-350^{\circ} \mathrm{C}$ & $350-400^{\circ} \mathrm{C}$ & $400-450^{\circ} \mathrm{C}$ & $450-500^{\circ} \mathrm{C}$ \\
\hline KTK & - & 22 & 30 & 25 & 10 \\
\hline \multirow{3}{*}{$\mathrm{KTK} / \mathrm{CrCl}_{3}$} & $4: 1$ & 12 & 19,6 & 31,8 & 12 \\
\cline { 2 - 6 } & $8: 1$ & 10 & 17 & 44 & 18 \\
\cline { 2 - 6 } & $12: 1$ & 12 & 16 & 41 & 16,9 \\
\cline { 2 - 6 } & $16: 1$ & 20 & 30,6 & 25,8 & 11,2 \\
\hline
\end{tabular}

Cədvəldən göründüyü kimi, Al-un nisbəti (8:1)-dən 16:1-dək yüksəldikcə heksen1-in oliqomerləşmə dərəcəsi azalır və $16: 1 \mathrm{~mol}$ nisbətində demək olar ki, KTK-dan az fərqlənir. Komponentlərin aşağ 1 mol nisbətlərində $(4: 1)$ isə heksen-1-in oliqomerləşməsi prosesində konversiya dərəcəsinin azalması müşahidə edilmişdir. Bu onu sübut edir ki, götürülən metal duzunun miqdarı bimetal mərkəzlərin tam formalaşması üçün kifayət etmir və artıq miqdarda götürülmüş $\mathrm{CrCl}_{3}$ mexaniki qarışıq şəklində sistemdə qalaraq heksen-1-in konversiyasına mənfi təsir göstərir.

Aparılan təcrübələrə əsasən bimetallik katalitik kompleksin iştirakı ilə heksen-1-in oliqomerləşməsi prosesi üçün optimal şərait: reaksiya müddəti - 60 dəq., katalizatorun qatılığ 1 - $0.5 \%$ küt., komponentlərin mol nisbəti $\mathrm{Al}: \mathrm{Cr}=8: 1$, temperatur $-50^{\circ} \mathrm{Cmüəyyən}$ edilmişdir. 
Müəyyən edilmiş optimal şəraitdə xrom duzu ilə modifikasiya olunmuş yeni katalitik kompleksin iştirakı ilə heksen-1-in oliqomerləşməsi zamanı yüksək çıxım və fiziki göstəricilərə malik, dar molekul-kütlə paylanması ilə xarakterizə olunan oliqomerlər almaq mümkündür.

Yeni katalitik sistemlərin alınması yüksək istismar xüsusiyyətləri ilə digər yağlardan fərqlənən polialfaolefin yağlarının fiziki-kimyəvi xassələrinin tənzimləməsi və bu məhsulların keyfiyyət göstəricilərinin yaxşılaşması üçün mühüm addımdır.Müasir analiz metodlarından istifadə etməklə heksen1-in oliqmerləşməsindən alınan məhsulların tərkibi, fiziki-kimyəvi xüsusiyyətləri tədqiq olunmuşdur [20].Tədqiq olunan oliqomer məhsulların termiki xüsusiyyətləri termoqravimetrik (TG) və differensial termiki analiz (DTA) metodları vasitəsilə öyrənilmiş və göstərilmişdir ki, termoqravimetrik əyrilər xarakter baxımından bir-birinə oxşardır, lakin xrom duzu ilə modifikasiya olunmuş katalitik sistemin iştirakında alınan yağların termiki davamlılığında sürüşmə nəzərə çarpır. Әgər heksen-1-in oliqomerloşdirilməsi üçün katalizator kimi KTK götürüldükdə DTGəyrisində maksimum $285^{\circ} \mathrm{C}$-də qeydə alınmışsa, KTK-Cr iştirakında alınan yağın parçalanma sürətinin maksimumu $330^{\circ} \mathrm{C}$-dək yerini dəyişmiş, nəticədə bu fərq $45^{\circ} \mathrm{C}$ təşkil etmişdir [20]. Yağ nümunələrinin İQ

spektrlərinin tədqiqi zamanı dalğa uzunluğu $3000 \mathrm{sm}^{-1}$-də doymamış karbohidrogenlərə, $1500-400 \mathrm{sm}^{-1}$ diapazonunda isə yă molekullarının skelet rəqslərinə uyğun udulma zolaqları müşahidə olunmuşdur.

$$
\text { Yağın tərkibindo aromatik }
$$

karbohidrogenlərə xas olan siqnalları ültrabənövşəyi spektroskopik metodla dəqiq müəyyənləşdirmək mümkündür. Tədqiqatlar zamanı müəyyən olunmuşdur ki, ikiqat rabitəli doymamış karbohidrogenlərə aid edilən intensiv 195-200 nm udulma zolaqları zəif də olsa müşahidə olunur, lakin aromatik karbohidrogenlərə aid olan siqnallar (260-280 $\mathrm{HM}$ ), praktiki olaraq yoxdur. Bu isə kation tipli katalizatorlardan fərqli olaraq sintez olunmuş katalitik sistemlərin iștirakı ilə olefinlərin oliqomerləşməsi zamanı dehidrogenləşmə və tsiklləşmə proseslərinin baş verməməsini göstərir. Alınan yağların tərkibində aromatik karbohidrogenlərin olmamas1, hidrogenləşmədən sonra onlardan tibbdə "A $\breve{g}$ yă̆" kimi istifadə olunması perspektivləri açır.

$\mathrm{KTK}-\mathrm{Cr}$ iştirakı ilə $40^{\circ} \mathrm{C}, 50^{\circ} \mathrm{C}, 60^{\circ} \mathrm{C}$ temperaturlarda sintez edilmiş $300-450^{\circ} \mathrm{C}$ yağ fraksiyalarının termooksidləşdirici stabilliyini öyrənmək məqsədi ilə ГOCT 11063-77 üzrə sınaqlar aparılmış və nəticələr aşağıdakı qrafikdə verilmişdir.

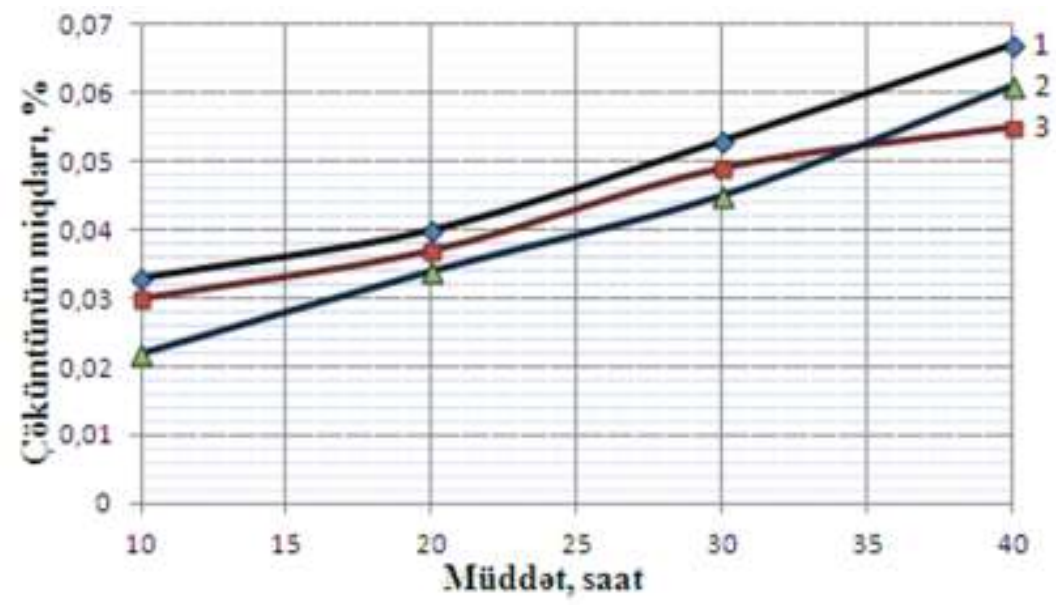

Şəkil. Müxtəlif temperaturlarda alınmış $300-450^{\circ} \mathrm{C}$ yağ fraksiyalarında $200^{\circ} \mathrm{C}$-də çöküntü əmələ gəlməsinin zamandan asılılı̆̆ $1\left(1-40^{\circ} \mathrm{C} ; 2-50^{\circ} \mathrm{C} ; 60^{\circ} \mathrm{C}\right)$

Qrafikdən göründüyü kimi, yăg asılı olaraq cüzi dəyişir. 40 saat ərzində $40^{\circ} \mathrm{C}$, fraksiyalarında çöküntünün miqdarı vaxtdan $50^{\circ} \mathrm{C}, 60^{\circ} \mathrm{C}$ temperaturlarda sintez edilmiş 
$300-450^{\circ} \mathrm{C}$ yağ fraksiyalarında əmələ gələn çöküntünün miqdarı müvafiq olaraq $0.067 \%$, $0.055 \%, 0.061 \%$ təşkil edir. Müqayisə üçün tədqiqatlar aparılaraq müəyyən olunmuşdur ki, T-46 mineral baza yağında çöküntünün miqdar1 uyğun olaraq, 10 saat ərzində - $0.8 \%$, 20 saatda $-1.5 \%, 30$ saatda $-2 \%, 40$ saatda - $2.25 \%$ olmuşdur. Oldə edilən nəticələrdən göründüyü kimi, KTK-Cr iştirakı ilə heksen-1in oliqomerləşməsindən alınan yağ fraksiyaları yüksək termostabillik xassəsi göstərir və keyfiyyətli muhərrik yağları kimi xüsusi əhəmiyyətə malikdir.

Beləliklə, katalitik sistemin seçilməsindən asılı olaraq alınan yağların fiziki-mexaniki xassələrini tənzimləmək mümkündür və bununla da gələcəkdə tələb olunan yüksək keyfiyyət göstəricilərinə malik polialfaolefin yağları almaq imkanı yaranır.

\section{References}

1. Kramer A., Surana P., Nandapurkar P.J., Yang N. High viscosity polyalphaolefins based on 1-hexene, 1-dodecene and 1tetradecene. Pat. U.S. 7547811 B2(2009).

2. Tsvetkov O.N. Poly- $\alpha$-olefin oils: chemistry,technology and application. Moscow.2006,190p.

3. Xiaoqiao Y., Benxian S., Lan Y., Lei L., Hui S., Jichang L. Synthesis of polyalphaolefines on $\quad \mathrm{AlCl}_{3} / \mathrm{TiCl}_{4}$ catalyst.China petroleum processing and petrochemical technology. 2012, vol. 14, no. 2, pp.55-59.

4. Surana P., Norman Y., Pramod N. High viscosity PAOs based on 1- decene/1dodecene. Pat. US 7550640 B2(2009)

5. Ding H., Zhang B.Y., Liu J. Study on preparation process of lubrication from 1decene with acidic ionic liquid catalyst. Petroleum Science and Technology. 2009, vol. 27, no. 17, pp.1919-1925.

6. RudnikL.R. Synthetics, Mineral Oils and Bio-based Lubricants. Chemistry and technology. Taylor\&Francis, 2006, 894 p.

7. Yadav D., Doshi N.S. Development of green process for poly- $\alpha$-olefin based lubricants. Green Chemistry.2002, vol. 4, pp. $528-540$.

8. Azizov A.H., Aliyeva R.V., Seidova Kh.H., Karayeva E.M., Nazarov I.G., Abdullayeva A.M. Oligomerization and alkylation decene-1 in the presense chloroaluminate ionic liquids. American Journal of Chemistry and Application. 2015,vol. 2 (3), pp.21-26.

9. Knowles D.C., Fabian J.R., Kosover V, Ferrarotti S., Fox E.B. Polyalphaolefins and processes for forming polyalphaolefins.
United States patent US 20090281360. 2009, Nov. 12.

10. Tsvetkov O.N., Toporishcheva R.I., Kolesova G.E., Cheremiskin A.L., Shamsutdinov V.G., etc. Synthesis of the high-viscosity poly-alpha-olefins andexploration of the industrial oil production at PAOO-20. World of Oil Products, 2010, no.3, pp.26-29.

11. Azizov A.G., Samedova F.I., Ibragimova M.D., Gasanova R.Z., Azmamedov N.G., Askerova A.S. Synthetic oligodecene bases of the viscous transmission oils.Petroleum Refining and Petrochemistry. 2009, no. 8, pp.18-21.

12. Gasanova R.Z., Askerova A.S. Modern state of production and utilization of environmentally safe poly- $\alpha$-olefin oils. Azerbaijan Oil Industry. 2007, no. 8, pp.6067.

13. Saptarshi R, Peddy V.C.R., Netten V.C. Poly- $\alpha$-olefin-based synthetic lubricants: a short review on various synthetic routes. Lubrication Science. 2012, vol. 24, no. 1, pp. 23-44.

14. Rustamov M.I, Babaev A.I, Ibragimov Kh.D. The possibility of solving a number of problems of modern petrochemistry and oil refining in Azerbaijan on the basis of a new catalytic complex. Processes of petrochemistry and oil refining. 2006, no.1, pp.48-70.

15. Ibragimov H.D., Seidov N.M., Ismailov E.G., Ibragimova Z.M.,Gasimova K.M., Kolchikova I.V.,Gasimova G.F. The new effective bimetallic catalytic complex of $\mathrm{C}_{5}$ fraction processing of pyrocondensate. Chemical problems, 2012, no.3, pp. 305- 
315.

16. Ibragimov H.C., Gasimova K.M., Ibragimova Z.M. Synthesis and study of bime-tallic catalytic systems formed in situ by aluminum, 1, 2-dichloroethane and Fe (III), Ni (II), Mn (II) chlorides. Journal of Advances in Chemistry, 2013, vol. 3, no. 1, pp.120-132.

17. Ibragimov H.C, Gasimova K.M., Ibragimova Z.M, Alizadeh Sh.A, Kolchikova I.V., Aleskerova S.M. Application of nanosized carbon aluminum-containing bimetallic catalyst complex in the oligomerization processes. Azerbaijan Chemical Journal, 2016, no 4, pp.64-68.

18. Ibrahimov H.J., Alizadeh Sh.A., Guliyev

A.D., Asadzadeh R.N., Huseynova M.A., Zamanova L.S. Investigation of aluminum-containing catalytic complex modified by chromium salt. Processes of Petrochemistry and Oil refining (PPOR). 2018, vol. 19, no. 4, pp.405-410.

19. Ibragimov H.C., Alizadeh Sh.A., Amirov F.A., Zamanova L.S. Impact of various parameters to oligomerization process of hexen-1 with participation of bimetallic catalytic complex. Chemical Problems. 2018, no.1, pp.86-92.

20. Ibragimov H.C., Alizade Sh.A. Investigation about physical-chemical properties of products oligomerization of hexene-1. Azerbaijan Oil Industry, 2018, no. 9, pp.67-70.

\title{
RESEARCH INTO OF HEXEN-1 OLIGOMERIZATION PROCESS IN THE PRESENCE OF CATALYTIC COMPLEX MODIFIED WITH CHROMIUM SALT
}

\author{
Sh.A. Alizadeh \\ Institute of Petrochemical Processes named after Y.Mammadaliyev, \\ AZ 1025, Baku, Khojali Avenue, 30 \\ Fax: (+99412) 490-24-76, e-mail: selizade180@gmail.com
}

The effect of various parameters on the process hexen-1 oligomerixation was examined and optimal process conditions revealed. Composition of oligomerization products and some physical properties were analyzed through mehods of physical and chemical analysis. It found that under optimal conditions in the presence of the catalyst, it is possible to obtain polyalphaolefin oils with high output and physical and mechanical properties.

Keywords: modification, oligomerization, hexen-1, polyalphaolefin oils

\section{ИССЛЕДОВАНИЕ ПРОЦЕССА ОЛИГОМЕРИЗАЦИИ ГЕКСЕНА-1 В ПРИСУТСТВИИ КАТАЛИТИЧЕСКОГО КОМПЛЕКСА, МОДИФИЦИРОВАННОГО СОЛЬЮ ХРОМА}

\author{
Ш.А.Ализаде
}

Институт нефтехимических прочессов им акад. Ю. Мамедалиева Национальной АН Азербайджана

AZ 1025 Баку, пр.Ходжаль, 30; Fax: (+99412) 490-24-76

e-mail: selizade180@gmail.com

Исследовано влияние различных параметров на прочесс олигомеризации гексена-1 в присутствии алюминиевого комплекса, модифицированного солью хрома $\left(\mathrm{CrCl}_{3}\right)_{6}$ режсие іп situи определень оптимальные условия процесса. Состав продуктов 
олигомеризации, некоторые физические свойства изучены методами физико-химического анализа. Установлено, что при оптимальных условиях в присутствии исследуемого катализатора возможно получение поли-альфа-олефиновых масел с высокими выходами и показателями физико-механических свойств.

Ключевые слова: модифицирование, олигомеризация, гексен-1,поли-альфа-олефиновые масла 